\title{
Identification of sex and age for Egyptians using computed tomography of the first lumbar vertebra
}

\author{
Nazih Ramadan *iD, Mervat Hamdy Abd El-Salam, Amani Fahmy Hanon, Naglaa Farid El-Sayed \\ and Ahmed Yosri Al-Amir
}

\begin{abstract}
Background: Identification of bony remains and other decomposed parts of human is of great importance not only for legal but also for humanitarian reasons. However, in certain instances due to burial factors or in cases of explosion disasters, many of large bones may be destroyed or incomplete. For age and sex identification, vertebrae aren't well studied; however, many vertebrae showed high accuracy rates for sex identification.

Methodology: One hundred and twenty-three Egyptian patients were included in the current study; 62 were females and 61 were males (age from 10 to 64 years). Abdominal Computer tomography (CT) scans were done for those patients in the Department of Radiology in kasralainy faculty of medicine, Cairo University after they gave informed consent. Fifteen linear measurements were taken for the first lumbar vertebra (L1) to assess age and sex.

Results: Male patients showed larger mean values most of measurements of the first lumbar vertebra than females and sex was determined at accuracy rate of $84.6 \%$. Moreover, significant correlation was found for age and majority of measurements; but unfortunately it was weak correlation.

Conclusion: Sex can be estimated from first lumbar vertebrae with reasonable levels of accuracy in legal and humanitarian situations when skeletal remains are incomplete. However, it seems that vertebral measurements of lumbar vertebra aren't useful indicator for age estimation with further studies needed on larger samples and on different age groups.
\end{abstract}

Keywords: Age, Sex, Egyptians, Computed tomography, Lumbar vertebrae

\section{Background}

Identification of human bony remains and any other human parts is of great importance not only for legal but also for humanitarian reasons (Zheng et al., 2012), for example in mass disasters or in case of missed persons; when it's necessary to identify and know the dead, especially for the information of his surviving relatives (Saukko and Knight, 2016). Skeletal remains examined in archeological or forensic scenes may be destroyed due to burial conditions or any other conditions, as disarticulation, scattering, and commingling. Therefore, it is important to develop new methods that help in sex and age identification from a wide range of skeletal parts (Marlow and Pastor, 2011).

\footnotetext{
* Correspondence: drnazihramadan@kasralainy.edu.eg

Cairo University Kasr Alainy, Faculty of Medicine, Cairo, Egypt
}

Many authors were able to identify sex from measurements taken from the second cervical vertebra at accuracy rates ranged from 70\% to $92.9 \%$ (Bethard and Seet, 2013; Gama et al., 2015; Torimitsu et al., 2016; Wescott, 2000). Moreover they proved that the second cervical vertebra is a good sex identifier especially when bigger bones are damaged.

Hou et al. (2012) and Yu et al. (2008) proved that the last thoracic vertebra (T12) showed significant sexual difference (Badr El Dine and El Shafei, 2015); they have reached accuracy rates of $90 \%$ and $94.2 \%$ respectively for sex determination from T12 measurements (linear measurements of vertebral body and processes) (Ramadan et al., 2017). Moreover, different vertebral measurements taken from the first lumbar vertebra (L1) had great role in sex identification at high accuracy rates 
according to (Zheng et al., 2012); they proved that accuracy rates of five measurements, related to the vertebral body, were more than $80 \%$.

In addition to sexually dimorphic characteristics, Morphological changes of the vertebrae in the form of marginal bony lipping or osteophytes formation, have great role in understanding ageing patterns (Kacar et al., 2016; Snodgrass, 2004). However, moderate to severe degenerative changes begin around age of 50; as lumbar vertebrae still exhibit striations between ages between 24 and 49 years, and may show only mild lipping or macroporosity, while Vertebrae older than 50 years usually show absence of striations on the vertebral body, moderate to excessive vertebral degeneration, as osteophytes, lipping, and macro-porosity (Smith, 2010). So, it may be of interest to assess how non-pathologic aging effects, independent from degenerative alterations, are reflected on the vertebrae (Ruhli et al., 2005). Although Ruhli and his colleagues reached that only $20 \%$ of all taken vertebral measurements demonstrate significant changes by aging, Mavrych et al. (2014) show significant correlations between all dimensions of the vertebral body and age after exclusion of osteophytes. So, the current study tried to assess the effects of normal aging on lumber vertebrae, independently from age-related degenerative changes, using MSCT.

Previous studies have been conducted on Egyptian samples to identify sex from different skeletal elements as talus measurements (Abd-elaleem et al., 2012), hand bones (Eshak et al., 2011), maxillary sinus (Amin and Hassan, 2012), foot and patella (Abdel Moneim et al., 2008), however, no Egyptian studies had been done on the first lumbar vertebra to determine both age and sex. Single study (Badr El Dine and El Shafei, 2015) was conducted for only sex determination from the first lumbar vertebra (L1) among Egyptians; they tested 24 measurements taken from CT of T12 and L1 to evaluate their role in sex identification. Although the same measurements were taken from both vertebrae with the same method, the results showed great difference. For T12; 14 measurements of 24 were significant and sex was predicted at accuracy rate of 93.1, while for L1; only seven measurements of 24 were significant and sex identification accuracy was very low (68\%) (Badr El Dine and El Shafei, 2015). For this reason, this study aims to reassess the role of the first lumber (L1) vertebra in sex identification in addition to age estimation which wasn't tested in the previous study.

\section{Subjects and methods}

\section{Aim of the current study}

We aim to establish parameters for identification of age and sex for Egyptians based on the first lumbar vertebral measurements.

\section{Subjects}

One hundred and twenty-three Egyptian patients were included in the current study; 61 males (their ages between 10 and 64) and 62 females (age between 10 and 60 years). Abdominal Computer tomography (CT) scans were done for those patients in the Department of Radiology in kasralainy faculty of medicine, Cairo University after they gave informed consent. Patients who seek medical advice or treatment in the Cairo university hospitals are usually from low or moderate socioeconomic classes. The vertebrae used were free from any traumatic and pathological diseases. Also we excluded any vertebrae showing moderate to severe degenerative changes, as severe changes may make border distortion and reading errors. Also we aim to evaluate aging role on vertebral measurements independent of degenerative alterations.

This study was conducted after being approved and ethically accepted by the ethical and the scientific committee of kasralainy medical school in University of Cairo.

\section{Methods}

By the aid of the software (Syngo VB 42) and imaging machine (SOMATOM 78830, Siemens, made in Germany), scan was adjusted in bone window with sharpness $B 70$ and $1.5 \mathrm{~mm}$ slices width to acquire optimum visualization. To minimize measurement errors, majority of images were adjusted to be maximum intensity projection (MIP) images. This mentioned protocol was used identically for all subjects to avoid technical errors.

Fifteen linear vertebral measurements were measured and taken from the first lumbar vertebra (Table 1 and Fig. 1) in the workstation by forensic pathologist after being trained and supervised by senior consultant radiologist. The 15 measurements included; measurements of the body of the vertebrae as (Upper border (end plate) depth (EPDu), Upper border (end plate) width (EPWu), lower border (end plate) depth (EPDl), Height of anterior border of the body of the vertebra (XHA), lower border (end plate) width (EPWl), Height of the posterior border of the body of the vertebra (XHP)); dimensions of vertebral foramen (lenghth (LVF) and width (WVF)); pedicle dimensions (width (PW) and height $(\mathrm{PH})$ ); measurements of spinous process (length (SPL) and height $(\mathrm{SPH})$ ); transverse process dimensions (diameter (TD) and distance (TDm)) and Vertebral length (VL)). These measurements were adopted from measurements taken by (Zheng et al., 2012) and (Badr El Dine and El Shafei, 2015); with only one difference as they took their measurements from 3 dimensional (3D) images of CT which wasn't available for us.

\section{Statistical analysis}

Data was collected in excel sheet using Microsoft excel 2010 and the statistical analysis package (SPSS) last 
Table 1 Description of Measurements taken from first lumbar vertebra (L1)

\begin{tabular}{|c|c|c|c|}
\hline Measu-rement & Description & Measure-ment plane ${ }^{a}$ & Adjustment Plane $^{\mathrm{b}}$ \\
\hline EPDu & $\begin{array}{l}\text { Measurement taken in between the most anterior and the most } \\
\text { posterior edges of upper border of the body of the vertebra } \\
\text { (upper endplate) }\end{array}$ & \multirow[t]{8}{*}{ MIP Sagittal } & \multirow[t]{8}{*}{$\begin{array}{l}\text { In axial and coronal planes to obtain } \\
\text { the best view for L1 center }\end{array}$} \\
\hline EPDI & $\begin{array}{l}\text { Measurement taken in between the most anterior and the } \\
\text { most posterior edges of lower border of the body of the } \\
\text { vertebra (lower endplate) }\end{array}$ & & \\
\hline $\mathrm{XHA}$ & $\begin{array}{l}\text { taken between the uppermost and lowermost points for } \\
\text { the anterior body border }\end{array}$ & & \\
\hline $\mathrm{XHP}$ & $\begin{array}{l}\text { taken between uppermost and lowermost points for the } \\
\text { posterior body border }\end{array}$ & & \\
\hline LVF & $\begin{array}{l}\text { Internal sagittal length of foramen of the vertebra from inner } \\
\text { part of posterior border of the spinous process to inner aspect } \\
\text { of posterior border of the body of vertebra }\end{array}$ & & \\
\hline SPL & $\begin{array}{l}\text { From most posterior edge of the spinous process to inner } \\
\text { posterior border of vertebral foramen }\end{array}$ & & \\
\hline SPH & $\begin{array}{l}\text { Measurement from superior to inferior borders of the vertebral } \\
\text { spinous process at junction of posterior and middle one third }\end{array}$ & & \\
\hline$V L$ & $\begin{array}{l}\text { Measured From the most posterior endpoint of the spinous } \\
\text { process to the center of an imaginary line passing with anterior } \\
\text { border of the body }\end{array}$ & & \\
\hline $\mathrm{PH}$ & Measured from superior to inferior borders of the left pedicle & MIP Sagittal & In axial plane \\
\hline EPWI & $\begin{array}{l}\text { Distance taken between the two lateralmost points in the } \\
\text { lower border of the body of the vertebra (lower endplate) }\end{array}$ & \multirow[t]{2}{*}{ MIP Coronal } & \multirow[t]{2}{*}{$\begin{array}{l}\text { In axial and sagittal planes for best } \\
\text { view of body center }\end{array}$} \\
\hline EPWu & $\begin{array}{l}\text { Distance taken between the two lateralmost points in the } \\
\text { upper border of the body of the vertebra (upper endplate) }\end{array}$ & & \\
\hline WFV & maximum inner width of foramen of the vertebra & \multirow[t]{4}{*}{ Axial } & \multirow{4}{*}{$\begin{array}{l}\text { In sagittal plane at level passing the } \\
\text { pedicle center }\end{array}$} \\
\hline PW & $\begin{array}{l}\text { Distance taken from the most lateral to the most medial } \\
\text { edges for left pedicle }\end{array}$ & & \\
\hline TDm & Measured between lateral edges of both transverse processes & & \\
\hline TD & $\begin{array}{l}\text { Measured from inner border of the lamina to the right } \\
\text { transverse process tip }\end{array}$ & & \\
\hline
\end{tabular}

\section{the primary plane in which the measurement was taken}

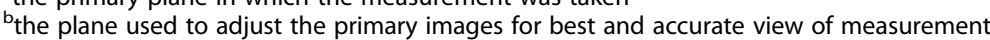

PW, WVF, TDm and TD weren't taken in MIP because either the measurement is small so may be distorted in MIP images or the measurement borders aren't well identified or not clear in MIP images

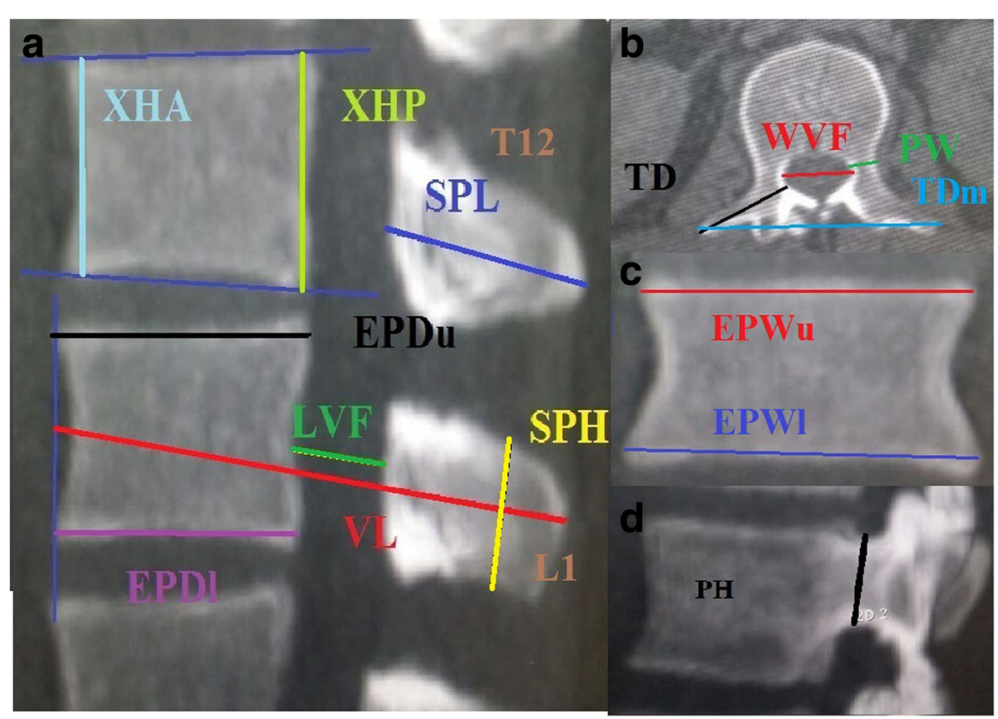

Fig. 1 Measurements taken from the first lumbar vertebra. a for sagittal images, $\mathbf{b}$ for axial images, $\mathbf{c}$ for sagittal images at pedicle level while $\mathbf{d}$ for coronal images. In (a) image measurements are demonstrated on T12 and L1 due to large number of measurements 
version (version 21) was used for the analysis of data. To compare qualitative data, we used Independent T-test, and variables that revealed significant correlation $(P<$ $0.05)$ with sex were then included and tested in stepwise discriminant function analysis. While for quantitative data Pearson correlation was used and Pearson coefficient was able to describe both correlation direction (positive or negative) and power (weak correlation if $<0.5$ ) (moderate correlation from 0.5 and 0.7) (strong correlation if $>0.7$ ). Then, factors showing significant association with age were tested in linear regression models (Dawson and Trapp, 2004).

\section{Results}

Descriptive statistics of this study showed statistically significant difference between male and female groups (with males larger than females) for all measurements of the first lumbar vertebra except length of the vertebral foramen (LVF) (Table 2).

In addition sex can be predicted from L1 measurements using the following equation at accuracy of $84.6 \%$ : $\mathrm{S}=0.261$ EPWu -10.789 .

If the equation result was more than (zero), the sex is considered male, otherwise sex is female.

Correlation studies proved that significant correlation was found for age and all vertebral dimensions (Table 3) except for some measurements (TD, LVF, TDm and $\mathrm{PW})$. However, these correlations weren't strong $(R<$
0.05). Figure 2 shows correlation between age and SPH which is also weak correlation.

In addition, the results of the linear regression analysis (Table 4), for the proved significant measurements by bivariate analysis, revealed that age could be estimated from L1 using any of the following models:

$$
\begin{aligned}
& \text { Age }=-10.685+2.452 * \mathrm{EPDu} . \\
& \text { Age }=-10.685+0.766 * \mathrm{SPH} . \\
& \text { Age }=-10.685+2.155 * \mathrm{WVF} . \\
& \text { Age }=-10.685+3.569 * \mathrm{XHP} .
\end{aligned}
$$

For this analysis the $R^{2}=0.471$ and the adjusted $R^{2}$ is 0.348 , so again these equations aren't strong enough to estimate age with high accuracy rates.

\section{Discussion}

In the current study, males were significantly larger in means of all measurements of L1 than females except for LVF and the most accurate measurement was EPWu with accuracy of $84.6 \%$. These results were nearly the same as those of Zheng et al. (2012); they also concluded that nearly all measurements were significant larger in males and the most accurate measurement was EPWu, similar to the current study, with sex correction rate of $88.6 \%$.

In accordance, Ostrofsky and Churchill (2015) concluded that South African males were significantly greater than females in most of L1 measurements. Although they used physical osteological examination

\begin{tabular}{|c|c|c|c|c|c|c|c|c|c|}
\hline & Males & & & & Females & & & & P. \\
\hline & Minimum & Maximum & Mean & S.D. & Minimum & Maximum & Mean & S.D. & \\
\hline Age & 10 & 64 & 36.4 & 13.8 & 10 & 60 & 37.9 & 13.2 & 0.549 \\
\hline EPDu & 23.3 & 41.7 & 32.8 & 3.6 & 23.3 & 35 & 28.9 & 2.3 & $0.000^{b}$ \\
\hline EPDI & 23 & 49 & 33.4 & 3.8 & 23 & 36.7 & 29.5 & 2.7 & $0.000^{b}$ \\
\hline $\mathrm{XHA}$ & 16 & 35 & 26.0 & 3.5 & 17.9 & 29 & 24.7 & 1.9 & $0.015^{\mathrm{a}}$ \\
\hline $\mathrm{XHP}$ & 17 & 33 & 28.4 & 3.3 & 18 & 29 & 26.0 & 1.8 & $0.000^{b}$ \\
\hline LVF & 10 & 18.7 & 14.2 & 1.8 & 10 & 17 & 13.8 & 1.7 & 0.174 \\
\hline SPL & 17.5 & 40 & 32.2 & 5.2 & 17.5 & 35 & 28.9 & 3.5 & $0.000^{b}$ \\
\hline $\mathrm{SPH}$ & 11 & 33 & 21.6 & 4.9 & 11.5 & 25 & 19.0 & 2.8 & $0.000^{b}$ \\
\hline$V L$ & 56 & 89 & 78.7 & 7.2 & 56 & 76 & 70.4 & 4.3 & $0.000^{b}$ \\
\hline $\mathrm{PH}$ & 9 & 19 & 15.8 & 2.3 & 9.5 & 18 & 14.2 & 1.3 & $0.000^{b}$ \\
\hline EPWu & 31.8 & 53 & 44.4 & 4.6 & 31.8 & 44 & 38.2 & 2.8 & $0.000^{b}$ \\
\hline EPWI & 24 & 55.1 & 46.8 & 5.7 & 33.5 & 45 & 40.2 & 2.7 & $0.000^{b}$ \\
\hline WVF & 19 & 29 & 24.2 & 2.2 & 18.5 & 26 & 22.5 & 1.8 & $0.000^{b}$ \\
\hline TD & 13 & 30 & 18.5 & 3.3 & 12.5 & 25.4 & 16.4 & 2.2 & $0.000^{b}$ \\
\hline TDM & 31 & 80 & 47.1 & 8.4 & 31 & 50 & 41.0 & 4.4 & $0.000^{b}$ \\
\hline PW & 6 & 13.1 & 9.3 & 1.6 & 4 & 11 & 7.7 & 1.5 & $0.000^{b}$ \\
\hline
\end{tabular}
(POE) of lumbar vertebrae, they reached that EPWu was the most accurate measurement with accuracy of $87.1 \%$.

Table 2 Male and female difference in measurements of L1 
Table 3 The correlation between age and L1 measurements

\begin{tabular}{lll}
\hline Measurements & $\begin{array}{l}\text { Pearson's } \\
\text { Correlation }\end{array}$ & $P$. value \\
\hline Height of anterior of the body & 0.329 & $0.000^{\mathrm{b}}$ \\
Height of posterior border of body & 0.263 & $0.001^{\mathrm{a}}$ \\
Length of the vertebral foramen & -0.034 & 0.705 \\
Upper end plate depth & 0.349 & $0.000^{\mathrm{b}}$ \\
Lower end plate depth & 0.282 & $0.002^{\mathrm{a}}$ \\
Transverse process distance & 0.226 & $0.012^{\mathrm{a}}$ \\
Vertebral length & 0.404 & $0.000^{\mathrm{b}}$ \\
Spinous process height & 0.441 & $0.000^{\mathrm{b}}$ \\
lower end plate width & 0.321 & $0.000^{\mathrm{b}}$ \\
Maximum width of the vertebral foramen & 0.391 & $0.000^{\mathrm{b}}$ \\
Upper end plate width & 0.357 & $0.000^{\mathrm{b}}$ \\
Transverse process diameter & 0.121 & $0.182^{\mathrm{b}}$ \\
Pedicle width & 0.069 & 0.447 \\
Spinous process length & 0.412 & $0.000^{\mathrm{b}}$ \\
Pedicle height & 0.218 & $0.016^{\mathrm{a}}$ \\
\hline
\end{tabular}

asignificant

${ }^{\mathrm{b}}$ highly significant

In addition, different L1 measurements were approved by many authors (Table 5) to be statistically higher in males than females.

Pastor (2005) showed that TDm was the most discriminative measurement for sex prediction from L1 with accuracy of $100 \%$ which was too high mostly because the sample was very old collection of white immigrant population from the 18th/19th century and method was physical osteological examination (POE). Also he used physical osteological examination (POE) of L1 for two modern samples (black and white), and reached accuracy rate of $85.1 \%$ for black using EPD \& EPW (mid length

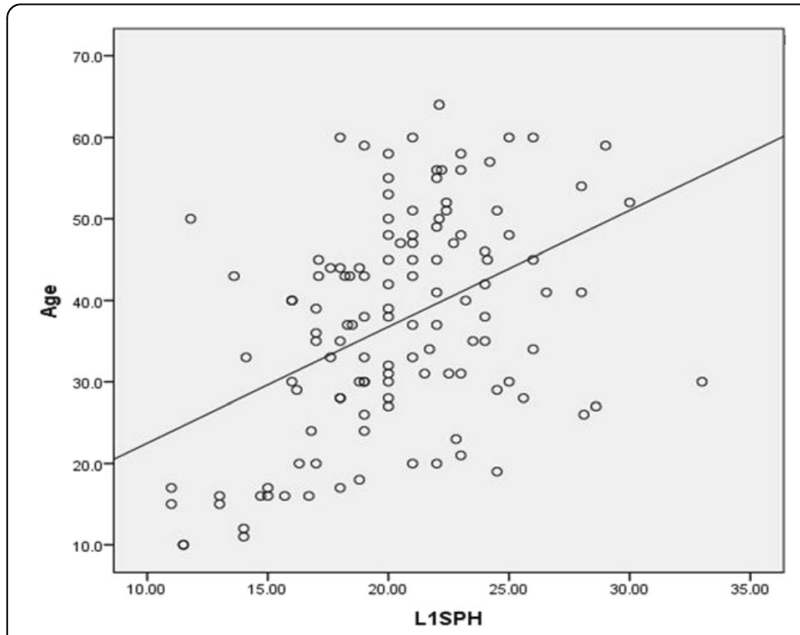

Fig. 2 Correlation between age and SPH of L1 not upper or lower border), and $91.8 \%$ for white using measurements not included in this study.

Although the study of Badr El Dine \& El Shafei (2015) was conducted on Egyptians, they showed that only seven of 24 measurements of L1 were significantly different between males and females with low accuracy rate $68 \%$. They took their measurements from 3D images which was different from this study (2D images were used) but this difference not assumed to make this difference in results as 3D images were used by Zheng et al. (2012) and showed high accuracy, so further studies on larger Egyptian samples are needed and should compare using 2D and 3D images. Moreover, Badr El Dine \& El Shafei (2015) reached that EPDu is the most accurate measurement which is different from the current study, may be due to larger number of used measurements.

In contrast, Ruhli et al. (2006) on historic Swiss sample, found that intervertebral foramen widths of L1 was slight greater in females than in males. These results were explained by methodological differences, possible inter-population variations and because the sample was old historic.

New emerging imaging modalities as magnetic resonance imaging (MRI), angiography and computer tomography (CT) allow visualization of nearly all anatomical and pathological structure with good quality and high resolution (Badr El Dine and El Shafei, 2015). Therefore, CT taken measurements are very accurate as caliper measurements of dry bones (Zech et al., 2012).

Although few studies used computer tomography for measurements taking from L1 for sex identification, no study, up to my knowledge, had tested computed tomography role in both sex and age identification from L1 measurements, or any other vertebrae.

Many of the previous studies (Kacar et al., 2016; Smith, 2010; Snodgrass, 2004) tested the role of osteophyte formation in age estimation, while only few studies (Mavrych et al., 2014; Ruhli et al., 2005) that excluded these degenerative changes.

In the current study, after exclusion of sever degenerative changes, significant correlation was found for age and majority of measurements; but unfortunately it was weak correlation, so vertebral measurements of L1 seem not to be useful indicator for age estimation.

In accordance, Ruhli et al. (2005) show low specific aging effect on vertebral shape, after degeneratively caused alterations are excluded. They conducted their study on two samples; modern Swiss and historic European samples using physical osteological 
Table 4 Linear regression coefficients for age estimation from L1

\begin{tabular}{|c|c|c|c|c|c|c|c|}
\hline \multirow[t]{2}{*}{ Measurements } & \multicolumn{2}{|c|}{ Unstandardized Coefficients } & \multirow{2}{*}{$\begin{array}{l}\text { Standardized Coefficients } \\
\text { Beta }\end{array}$} & \multirow[t]{2}{*}{$\mathrm{T}$} & \multirow[t]{2}{*}{$P$ value } & \multicolumn{2}{|c|}{ 95\% Confidence Interval for B } \\
\hline & $B$ & Std. Error & & & & Lower Bound & Upper Bound \\
\hline Constant & -10.685 & 15.779 & & -.677 & .500 & -41.995 & 20.625 \\
\hline EPDu & 2.452 & 1.174 & .655 & 2.089 & $.039^{*}$ & .123 & 4.782 \\
\hline EPDI & -1.204 & .942 & -.342 & -1.278 & .204 & -3.073 & .665 \\
\hline $\mathrm{XHA}$ & .419 & .913 & .089 & .459 & 648 & -1.394 & 2.231 \\
\hline $\mathrm{XHP}$ & 3.569 & 1.042 & .779 & 3.426 & $.001^{*}$ & 5.637 & 1.502 \\
\hline SPL & -.743 & .760 & -.258 & -.978 & .331 & -2.250 & .765 \\
\hline SPH & .766 & .394 & .237 & 1.946 & $.045^{*}$ & -.015 & 1.548 \\
\hline$V L$ & 1.484 & .811 & .798 & 1.830 & .070 & -.125 & 3.093 \\
\hline $\mathrm{PH}$ & -.214 & .906 & -.033 & -.236 & .814 & -2.011 & 1.583 \\
\hline EPWu & .115 & .676 & .042 & .171 & .865 & -1.226 & 1.457 \\
\hline EPWI & -.188 & .490 & -.078 & -.383 & .702 & -1.160 & .785 \\
\hline WVF & 2.155 & .842 & .348 & 2.558 & $.012^{*}$ & .484 & 3.827 \\
\hline TDM & .066 & .181 & .036 & .362 & .718 & -.294 & .425 \\
\hline
\end{tabular}

examination (POE). They revealed also that significant weak to moderate positive correlation was found for age and aproximatly $20 \%$ of measurements (mainly body diameters) of the seventh cervical (C7) vertebra, the first thoracic (T1) vertebra and the first lumbar vertebra, in males of modern sample. In historic samples, males showed nearly the same results of modern sample, while in females, some measurements showed correlation to age in contrast to modern sample. In contrast, Mavrych et al. (2014) proved that, in both males and females, there was significant correlation for all vertebral body measurements and age. This strong correlation can be explained by the bigger sample (1060 vertebrae) and the used age groups (age range 0-90 years divided into 11 age groups).

On the other hand, many researchers (Jankauskas, 1994; Kacar et al., 2016; Siemionow et al., 2011; Snodgrass, 2004; Watanabe and Terazawa, 2006) revealed significant statistical correlation for age and many measurements of different vertebrae. These correlations were due to the effect of vertebral degenerative changes, which is different from this study. Liguoro et al. (1994) concluded that the best age indicator of all cervical vertebral measurements was sagittal body diameter (SBD).

In addition, many studies (Alhadlaq and Al-Maflehi, 2013; Baccetti et al., 2006, 2002; Baidas, 2012; Baptista et al., 2012; Choi et al., 2016; Flores-Mir et al., 2006; Franchi et al., 2000; Mito et al., 2003, 2002; Uysal et al., 2006) revealed that the correlation for age and vertebral body height (using cervical vertebrae lateral radiography) or vertebral volume (using CT of cervical vertebrae), was strong and positive. However, these studies used different methodologies and were conducted on younger ages below 18 in order to detect maturation of cervical vertebrae as an age determination method in juveniles, which wasn't similar to the current study.

Table 5 Sex determination studies of first lumbar vertebra

\begin{tabular}{|c|c|c|c|c|c|c|}
\hline Study Authors & Study year & Study population & Taken measurements & Most accurate & Used method & $\overline{\text { Accuracy }}$ \\
\hline Present study & 2017 & Egyptian & fifteen measurements & EPWu & CT & $84.6 \%$ \\
\hline Badr El Dine \& El Shafei & 2015 & Egyptian & 24 (including our measurements) + ratios & EPDu & CT & $68 \%$ \\
\hline Ostrofsky \& Churchill & 2015 & S.African & 11 (7 in this study) & EPWu & Dry bone & $87.1 \%$ \\
\hline Zheng et al. & 2012 & Chinese & 29(including ours) + ratios & EPWu & CT & $88.6 \%$ \\
\hline Jelaca-Tavakoli \& Lewis & 2010 & Americans & $V L$ & & Dry bone & $80 \%$ \\
\hline Ruhli et al. & 2006 & Swiss & LVF & & Dry bone & \\
\hline Pastor & 2005 & white immigrant & 12 (9 in this study) & TDm & Dry bone & $100 \%$ \\
\hline Pastor & 2005 & American & 14 (only 9 in this study) & EPD, EPW & Dry bone & $\begin{array}{l}85.1 \% \\
91.8 \%\end{array}$ \\
\hline Jankauskas & 1994 & Lithuanian & $\mathrm{XHA}, \mathrm{XHP}, \mathrm{TBD}$ & & Dry bone & \\
\hline
\end{tabular}




\section{Conclusion}

Sex can be estimated from first lumbar vertebrae with reasonable levels of accuracy in legal and humanitarian situations when skeletal remains are incomplete. However, it seems that vertebral measurements of lumbar vertebrae aren't useful indicator for age estimation with further studies needed on larger samples and on different age groups.

\section{Additional file}

Additional file 1: Supplementary data. (DOCX $71 \mathrm{~kb}$ )

\section{Abbreviations}

CT: Computer tomography; EPDI: Lower end plate depth; EPDu: Upper end plate depth; EPWI: Lower end plate width; EPWU: Upper end plate width; L1: First lumbar vertebrae; LVF: Length of the vertebral foramen; MIP: Maximum intensity projection; PH: Pedicle height; POE: Physical osteological examination; PW: Pedicle width; SPH: Spinal process height; SPL: Spinal process length; T12: Last thoracic vertebrae; TD: Transverse process diameter; TDm: Transverse process distance; VL: Vertebral length; WFV: Maximum width of the vertebral foramen; XHA: Maximum height of anterior vertebral body; XHP: Maximum height of posterior vertebral body

\section{Acknowledgements}

Not applicable

\section{Funding}

Not applicable

\section{Availability of data and materials}

The dataset(s) supporting the conclusions of this article is (are) included within the article (and its Additional file 1).

\section{Authors' contributions}

NR: Suggest the idea, took most of measurements, write the manuscript. MHA: Modified the idea, supervision, direction, revision of manuscript. AFH: Supervision, direction, revision of manuscript. NFE: Supervision, direction, revision of manuscript. AYA: Took some measurements, training of first author and supervision of measurements taking, revision of the methodology. All authors read and approved the final manuscript.

\section{Ethics approval and consent to participate}

This study was approved by the ethical committee of faculty of medicine, Cairo University. Informed consent was taken from patients before doing CT. in addition in case of minors (less than 18 years) informed consent by the parents or legal guardians.

\section{Consent for publication}

Not applicable

\section{Competing interests}

The authors declare that they have no competing interests.

\section{Publisher's Note}

Springer Nature remains neutral with regard to jurisdictional claims in published maps and institutional affiliations.

Received: 15 August 2017 Accepted: 21 November 2017 Published online: 06 December 2017

\section{References}

Abdel Moneim WM, Abdel Hady RH, Abdel Maaboud RM, Fathy HM, Hamed AM (2008) Identification of sex depending on radiological examination of foot and patella. Am J Forensic Med Pathol 29:136-140. doi:10.1097/PAF. ob013e318173f048
Abd-elaleem SA, Abd-elhameed M, Ewis AA (2012) Talus measurements as a diagnostic tool for sexual dimorphism in Egyptian population. J Forensic Legal Med 19:70-76. doi:10.1016/j.jflm.2011.12.003

Alhadlaq a M, Al-Maflehi NS (2013) New model for cervical vertebral bone age estimation in boys. King Saud Univ J Dent Sci. 4:1-5. doi:10.1016/j.ksujds. 2012.11.001

Amin MF, Hassan El (2012) Sex identification in Egyptian population using multidetector computed tomography of the maxillary sinus. J Forensic Legal Med 19:65-69. doi:10.1016/j.jflm.2011.10.005

Baccetti T, Franchi L, De Toffol L, Ghiozzi B, Cozza P (2006) The diagnostic performance of chronologic age in the assessment of skeletal maturity. Prog Orthod 7:176-188

Baccetti T, Franchi L, McNamara JA (2002) An improved version of the cervical vertebral maturation (CVM) method for the assessment of mandibular growth. Angle Orthod. 72:316-323. doi:10.1043/0003-3219(2002)072<0316: AIVOTC $>2.0 . \mathrm{CO}: 2$

Badr El Dine FMM, El Shafei MM (2015) Sex determination using anthropometric measurements from multi-slice computed tomography of the 12th thoracic and the first lumbar vertebrae among adult Egyptians. Egypt J Forensic Sci 5 : 82-89. doi:10.1016/j.ejfs.2014.07.005

Baidas L (2012) Correlation between cervical vertebrae morphology and chronological age in Saudi adolescents. King Saud Univ J Dent Sci 3:21-26. doi:10.1016/j.ksujds.2011.10.006

Baptista RS, Quaglio CL, Mourad LMEH, Hummel AD, Caetano CAC, Ortolani CLF, Pisa IT (2012) A semi-automated method for bone age assessment using cervical vertebral maturation. Angle Orthod 82:658-662. doi:10.2319/070111-425.1

Bethard JD, Seet BL (2013) Sex determination from the second cervical vertebra: a test of Wescott's method on a modern American sample. J Forensic Sci 58 101-103. doi:10.1111/j.1556-4029.2012.02183.X

Choi Y-K, Kim J, Yamaguchi T, Maki K, Ko C-C, Kim Y-I (2016) Cervical vertebral Body's volume as a new parameter for predicting the skeletal maturation stages. Biomed Res Int 2016:1-7. doi:10.1155/2016/8696735

Dawson B, Trapp R (2004) Basic and clinical biostatistics, 4th edn. Mcgraw-Hill Inc. , New York

Eshak GA, Ahmed HM, Abdel Gawad EAM (2011) Gender determination from hand bones length and volume using multidetector computed tomography: a study in Egyptian people. J Forensic Legal Med 18:246-252. doi:10.1016/j. jflm.2011.04.005

Flores-Mir C, Burgess CA, Champney M, Jensen RJ, Pitcher MR, Major PW (2006) Correlation of skeletal maturation stages determined by cervical vertebrae and hand-wrist evaluations. Angle Orthod 76:1-5. doi:10.1043/00033219(2006)076[0001,COSMSD]2.0.CO;2

Franchi L, Baccetti T, McNamara JA (2000) Mandibular growth as related to cervical vertebral maturation and body height. Am J Orthod Dentofac Orthop 118:335-340. doi:10.1067/mod.2000.107009

Gama I, Navega D, Cunha E (2015) Sex estimation using the second cervical vertebra: a morphometric analysis in a documented Portuguese skeletal sample. Int J Legal Med 129:365-372. doi:10.1007/s00414-014-1083-0

Hou WB, Cheng KL, Tian SY, Lu YQ, Han YY, Lai Y, Li YQ (2012) Metric method for sex determination based on the 12th thoracic vertebra in contemporary north-easterners in China. J Forensic Legal Med 19:137-143. doi:10.1016/j. jflm.2011.12.012

Jankauskas R (1994) Variability of vertebral column measurements in Lithuanian paleopopulation. Int J Anthr 9:137-151. doi:10.1007/BF02447602

Kacar E, Unlu E, Beker-Acay M, Balcik C, Gultekin MA, Kocak U, Eroglu S, Yucel A (2016) Age estimation by assessing the vertebral osteophytes with the aid of 3D CT imaging. Aust J Forensic Sci:1-10. doi:10.1080/00450618.2016.1167241

Liguoro D, Vandermeersch B, Guérin J (1994) Dimensions of cervical vertebral bodies according to age and sex. Surg Radiol Anat 16:149-155

Marlow EJ, Pastor RF (2011) Sex determination using the second cervical vertebra-a test of the method. J Forensic Sci 56:165-169. doi:10.1111/j.15564029.2010.01543.x

Mavrych V, Bolgova O, Ganguly P, Kashchenko S (2014) Age-related changes of lumbar vertebral body Morphometry. Austin J Anat 1:1014

Mito T, Sato K, Mitani H (2002) Cervical vertebral bone age in girls. Am J Orthod Dentofac Orthop 122:380-385

Mito T, Sato K, Mitani H (2003) Predicting mandibular growth potential with cervical vertebral bone age. Am J Orthod Dentofac Orthop 124:173-177. doi: $10.1016 /$ S0889540603004013

Ostrofsky KR, Churchill SE (2015) Sex determination by discriminant function analysis of lumbar vertebrae. J Forensic Sci 60:21-28. doi:10. $1111 / 1556-4029.12543$ 
Pastor, R.F. (2005). Sexual dimorphism in vertebral dimensions at the T12 / L1 junction, in: Proceedings of the American Academy of Forensic Sciences. Denver, CO: Publication Printers, New Orleans, LA., pp. 302-3.

Ramadan N, Abd El-Salam M, Hanoon A, El-Sayed N, Al-Amir A (2017) Age and sex identification using multi-slice computed tomography of the last thoracic vertebrae of an Egyptian sample. J Forensic Res 8:386. doi:10. 4172/2157-7145.1000386

Ruhli FJ, Muntener M, Henneberg M (2005) Age-dependent changes of the normal human spine during adulthood. Am J Phys Anthr 17:460-469. doi:10.1002/ajhb.20403

Ruhli FJ, Muntener M. Henneberg M (2006). Human osseous intervertebral foramen width. Am J Phys Anthr. 129, 177-88. doi:10.1002/ajpa.20263

Saukko P, Knight B (2016) The establishment of identity of human remains, in: KNIGHT's forensic pathology. CRC Press, Boca Raton, pp 95-132

Siemionow K, An H, Masuda K, Andersson G, Cs-Szabo G (2011) The effects of age, sex, ethnicity, and spinal level on the rate of intervertebral disc degeneration: a review of 1712 intervertebral discs. Spine (Phila Pa 1976) 36: 1333-1339. doi:10.1097/BRS.0b013e3181f2a177

Smith, A.K., 2010. Aging of the Lumbar Vertebrae Using Known Age and Sex Samples. Master thesis. Georgia State University

Snodgrass JJ (2004) Sex differences and aging of the vertebral column. J Forensic Sci 49:458-463

Torimitsu S, Makino Y, Saitoh H, Sakuma A, Ishii N, Yajima D, Inokuchi G, Motomura A, Chiba F, Yamaguchi R, Hashimoto M, Hoshioka Y, Iwase H (2016) Sexual determination based on multidetector computed tomographic measurements of the second cervical vertebra in a contemporary Japanese population. Forensic Sci Int 266:588.e1-588.e6. doi:10.1016/j.forsciint.2016.04.010

Uysal T, Ramoglu SI, Basciftci FA, Sari Z (2006) Chronologic age and skeletal maturation of the cervical vertebrae and hand-wrist: is there a relationship? Am J Orthod Dentofac Orthop 130:622-628. doi:10.1016/j.ajodo.2005.01.031

Watanabe S, Terazawa K (2006) Age estimation from the degree of osteophyte formation of vertebral columns in Japanese. Leg Med (Tokyo, Japan) 8:156-160. doi:10.1016/j.legalmed.2006.01.001

Wescott DJ (2000) Sex variation in the second cervical vertebra. J Forensic Sci 45: 462-466. doi:10.1520/JFS14707J

Yu S-B, Lee U-Y, Kwak D-S, Ahn Y-W, Jin C-Z, Zhao J, Sui H-J, Han S-H (2008) Determination of sex for the 12th thoracic vertebra by morphometry of three-dimensional reconstructed vertebral models. J Forensic Sci 53:620-625. doi:10.1111/j.1556-4029.2008.00701.x

Zech W-D, Hatch G, Siegenthaler L, Thali MJ, Lösch S (2012) Sex determination from os sacrum by postmortem CT. Forensic Sci Int 221:39-43. doi:10.1016/j. forsciint.2012.03.022

Zheng WX, Cheng FB, Cheng KL, Tian Y, Lai Y, Zhang WS, Zheng YJ, Li YQ (2012) Sex assessment using measurements of the first lumbar vertebra. Forensic Sci Int 219:285.e1-285.e5. doi:10.1016/j.forsciint.2011.11.022

\section{Submit your manuscript to a SpringerOpen ${ }^{\circ}$ journal and benefit from:}

- Convenient online submission

- Rigorous peer review

- Open access: articles freely available online

- High visibility within the field

- Retaining the copyright to your article

Submit your next manuscript at $>$ springeropen.com 